\title{
Body image satisfaction and weight concerns among a Mediterranean adult population
}

\author{
Maria del Mar Bibiloni, Josep LI Coll, Jordi Pich, Antoni Pons and Josep A. Tur
}

\begin{abstract}
Background: People tend to underestimate their current weight and overestimate their height minimizing health risk factors. The aim of this study was to assess body weight satisfaction, acceptance of body image, weight concern and dieting habits among a Mediterranean adult population.

Methods: Cross-sectional survey was carried out (2009-2010) in the Balearic Islands, Spain. A random sample $(n=1081)$ of young (18-35 y.o.) and middle-aged adults (36-55 y.o.) was interviewed and anthropometrically measured.

Results: Women were more dissatisfied being overweight, less dissatisfied being underweight, and more worried about weight gain than men. Middle-aged participants were more dissatisfied with body shape and underestimated body weight than young's. Employed women defined better current weight than unemployed, but unemployed were more worried about body weight gain. Overweight adults were more likely to underestimate their body weight but were also very worried about weight gain and more likely to report current dieting than their leaner counterparts. Active participants self-reported better body weight and were more satisfied with body image than sedentary.

Conclusions: Most of studied population reported body image dissatisfaction, but half of them are not worried about it. Women were more concerned about their body weight status. Practice of physical activity is a positive factor in self-perception. Holistic strategies are needed to avoid promoting unreal bodies, as well as the acceptance of the real body image.
\end{abstract}

Keywords: Balearic Islands, Body image, Weight concern, Physical activity, Obesity

\section{Background}

Overweight and obesity negatively impact quality of life, increase risk of developing chronic diseases and conditions, and are costly to healthcare systems [1-3]. The prevalence of obesity has tripled in many countries in the World Health Organization (WHO) European Region since the 1980s, and the number of those affected continues to rise at an alarming rate [4]. The prevalence of overweight and obesity in Spain in 2009 was 34.2 and $13.6 \%$, respectively [5], making it one of the European countries with the highest prevalence. Although overweight and obesity has remained mostly stable over the last decade in the Balearic Islands, approximately one in

\footnotetext{
* Correspondence: pep.tur@uib.es

Research Group on Community Nutrition and Oxidative Stress, University of Balearic Islands, and CIBEROBN (Physiopathology of Obesity and Nutrition CB12/03/30038), Guillem Colom Bldg, Campus, E-07122 Palma de Mallorca, Spain
}

four adults were reported as being overweight while one quality of life $[6,7]$ eases (hypertension, diabetes, hypercholesterolemia, asthma, among others) $[8,9]$ and predisposition to some infections [10]. However, weight loss can decrease obesity-related risks; just losing $5-10 \%$ of body weight gives health benefits, as lower blood pressure, LDL cholesterol, and triglycerides, among other cardiovascular

In weight control practices, any factor of body selfperception should be considered. An essential determinant of attempts to lose weight is awareness of having excessive weight status, which has a higher impact than the objective current weight status [14]. Earlier studies found that people tended to underestimate their current 
weight and overestimate their height [15], and artificially lower their risk factor profile which may have negative health outcome implications. Weight, height and body image self-perception may be influenced by many factors: physical, interpersonal, emotional, cultural [16] and socioeconomic, including the mass media (magazines and TV) that increase body image dissatisfaction and then induce subsequent eating disorders [17-19]. The 'ideal body' that is often portrayed in popular culture and mass media is a tall and thin frame which typically does not reflect the build of many women in the average population developing sterner judgment of their selfimage and sometimes becoming unnecessarily worried about their weight [20-22]. At the same time, the image that the mass media uses of severe obesity sends a confused message that high weights are required in order to define overweight [23]. Better knowledge of the factors of self-perception of body characteristic may be an important factor in weight control practices.

The aim of this study was to assess body weight satisfaction, acceptance of body image, weight concerns and dieting habits among a Mediterranean adult population.

\section{Methods}

\section{Study design}

The study was a population-based cross-sectional nutritional survey carried out in 2009-2010 in the Balearic Islands, Spain, a Mediterranean region. Obesity and Oxidative Stress (OBEX) survey (2009-2010), which was designed to obtain information on the health and nutritional status of the resident population in the Balearic Islands [24]. The target population consisted of all inhabitants of the Balearic Islands aged between 16 and 65 years old. The population sample was taken from residents registered on the Balearic Islands' official population census. The sampling technique included stratification according to geographical area and municipality size, inhabitants' age (3 strata) and gender and randomisation into subgroups, with Balearic Islands municipalities being the primary sampling units and individuals within these municipalities comprising the final sample units.

\section{Selection of participants, recruitment and approval}

This analysis was limited to young (18-35 years old) and middle-aged (36-55 years old) adult population $(n=$ 1081) that was interviewed one:one. The participation rate was $92.5 \%$ during 2009-2010. Non-participation rates included potential participants who declined to be interviewed (particularly over-55's) as well as involuntary non-participants who were excluded due to unavoidable constraints on them taking part. This sample size was considered sufficient to detect an overweight and obesity prevalence of $40 \%$ with $95 \%$ confidence level and a precision rate of $3.0 \%$. This sample size was also sufficiently large to estimate the prevalence of $95 \%$ confidence and a precision rate of 3.7 and $5.0 \%$ in the young $(n=704)$ and middle-aged $(n=377)$ population, respectively. Moreover, this sample size was considered sufficient to detect risk factors with a precision rate of $4.5 \%$ in men (young adults: 5.3\%; middle-aged adults: $8.5 \%$ ) and $3.8 \%$ in women (young adults: 4.9\%; middle-aged adults: $6.0 \%)$. Pregnant women were not considered in this study. Characteristics of the participants are shown in Table 1.

\section{Anthropometric measurements}

Anthropometric measurements were performed by two observers who underwent identical and rigorous training as an effort to minimize the effects of inter-observer variation. Data collection took place between September 1, 2009 and June 30, 2010. Height was measured using a mobile anthropometer (Kawe 44444, Asperg, Germany) to the nearest millimetre, with the subject's head in the Frankfurt plane. Body weight was determined to the nearest $100 \mathrm{~g}$ using a digital scale (Tefal, sc9210, Rumilly, France). The participants were weighed in bare feet and light clothes, noting and subtracting the weight of the clothes. Weight and height measures were used to calculate body mass index (BMI, $\mathrm{kg} / \mathrm{m}^{2}$ ). Normal-weight, overweight, obesity and excessive weight were defined as BMI 18.5-24.9 kg/m², BMI $25.0-29.9 \mathrm{~kg} / \mathrm{m}^{2}$, BMI $\geq 30 \mathrm{~kg} / \mathrm{m}^{2}$ and BMI $\geq 25 \mathrm{~kg} / \mathrm{m}^{2}$ respectively [4].

\section{Body weight estimation}

Body weight estimation was obtained using the difference between self-reported weight minus measured weight. Body weight estimation was defined as "correct" if the absolute difference between self-reported minus measured weight was less than $2.0 \mathrm{~kg}$, as "underestimated" if the difference was lower $-2.0 \mathrm{~kg}$ and as "overestimated" if the difference was higher $2.0 \mathrm{~kg}[25]$.

\section{Body image perception}

Perceived body image was measured using the Stunkard scale [26], which consists of silhouette drawings ranging from 1 to 9 with monotonic increments in the overweight percentage where 1 is the leanest silhouette and 9 is the largest silhouette. Separate figures for men and women were used (Fig. 1). From the 9 body figures, participants were asked to identify: (a) 'Which silhouette looks most like yourself?' and (b) 'Which silhouette would you like to look like?' The difference between perceived body image and desired body image was used to determine the level of dissatisfaction with current body image. Values other than zero represent dissatisfaction 
Table 1 Characteristics of the participants

\begin{tabular}{|c|c|c|c|}
\hline & All & $18-35$ y.o. & $36-55$ у.о. \\
\hline$n$ & 1081 & 704 & 377 \\
\hline Weight $(\mathrm{kg})^{a}$ & $64.2 \pm 11.9$ & $62.4 \pm 12.4$ & $66.9 \pm 13.3$ \\
\hline Height $(\mathrm{cm})^{\mathrm{a}}$ & $161.6 \pm 6.4$ & $162.1 \pm 6.4$ & $160.9 \pm 6.5$ \\
\hline BMI $\left(\mathrm{kg} / \mathrm{m}^{2}\right)^{\mathrm{a}}$ & $24.6 \pm 4.9$ & $25.9 \pm 5.2$ & $23.7 \pm 4.4$ \\
\hline Prevalence of overweight $(\%)^{b}$ & 24.8 & 20.9 & 30.6 \\
\hline Prevalence of obesity $(\%)^{b}$ & 11.0 & 7.7 & 15.9 \\
\hline Prevalence of excessive weight ${ }^{1}(\%)^{b}$ & 35.7 & 28.6 & 46.4 \\
\hline \multicolumn{4}{|l|}{ Origin $(\%)^{b}$} \\
\hline Balearic Islands & 66.0 & 66.4 & 65.2 \\
\hline Regions of Spain & 21.1 & 18.4 & 26.1 \\
\hline South America & 9.0 & 11.0 & 5.4 \\
\hline Other countries & 3.9 & 4.3 & 3.3 \\
\hline \multicolumn{4}{|l|}{ Educational level $(\%)^{\mathrm{b}}$} \\
\hline Low & 7.2 & 5.1 & 11.2 \\
\hline Medium & 53.0 & 58.1 & 43.6 \\
\hline High & 39.8 & 36.8 & 45.2 \\
\hline \multicolumn{4}{|l|}{ Professional profile $(\%)^{b}$} \\
\hline Student & 22.9 & 34.4 & 1.6 \\
\hline Unemployed & 7.7 & 6.5 & 9.9 \\
\hline Employed & 69.4 & 59.1 & 88.5 \\
\hline \multicolumn{4}{|l|}{ Leisure-time physical activity } \\
\hline Yes & 59.1 & 58.6 & 60.0 \\
\hline No & 40.9 & 41.4 & 40.0 \\
\hline
\end{tabular}

Abbreviations: $B M I$ body mass index, NS not significant

Prevalence of overweight: BMI $\geq 25-<30 \mathrm{~kg} / \mathrm{m}^{2}$; obesity: $\geq 30 \mathrm{~kg} / \mathrm{m}^{2}$; excessive weight: $\mathrm{BMI} \geq 25 \mathrm{~kg} / \mathrm{m}^{2}$

Data were expressed as ${ }^{\mathrm{a}}$ mean \pm standard deviation and ${ }^{\mathrm{b}}$ prevalence (\%)

with perceived body image. A positive value was indicative of the participant's wish to be thinner than their perceived current size, while a negative value reflected the participant's wish to be heavier than their current perceived size.

\section{Weight concern}

Weight concern was evaluated using the following question: "Are you worried about weight gain?" and the answers were limited to: 'Not at all, 'A little bit' and 'A lot'.

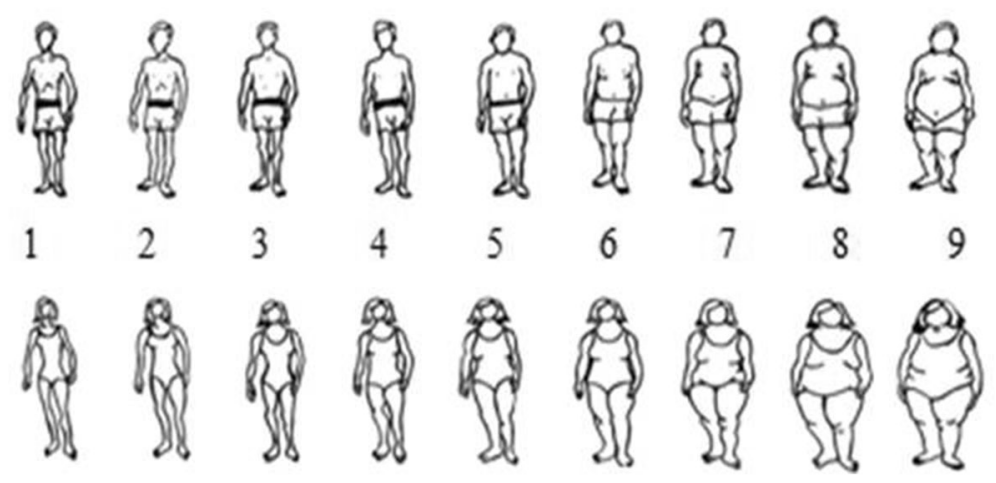

Fig. 1 Stunkard scale to measure perceived body image (adapted from [26]) 
Table 2 Weight Estimation according to socio-demographic variables, BMI distribution and LTPA $A^{a, b, c}$

\begin{tabular}{|c|c|c|c|c|c|}
\hline & Underestimation & Correct & Overestimation & Don't' know/Don't answer & $P$ \\
\hline Men $(n=451)$ & 20.6 & 60.5 & 6.0 & 12.9 & \\
\hline \multicolumn{6}{|l|}{ Age (years) } \\
\hline $18-35$ & 18.1 & 60.4 & 7.4 & 14.1 & \multirow[t]{2}{*}{0.032} \\
\hline $36-55$ & 27.2 & 60.8 & 2.4 & 9.6 & \\
\hline \multicolumn{6}{|l|}{ Origin } \\
\hline Balearic Islands & 19.8 & 61.4 & 5.9 & 12.9 & \multirow[t]{4}{*}{0.218} \\
\hline Regions of Spain & 24.7 & 61.8 & 7.9 & 5.6 & \\
\hline South America & 18.5 & 48.1 & 7.4 & 12.7 & \\
\hline Other countries & 22.2 & 55.6 & 0.0 & 22.2 & \\
\hline \multicolumn{6}{|l|}{ Educational level } \\
\hline Low & 20.7 & 51.7 & 13.8 & 13.8 & \multirow[t]{3}{*}{0.296} \\
\hline Medium & 18.9 & 59.8 & 6.3 & 15.0 & \\
\hline High & 23.2 & 62.8 & 4.3 & 9.8 & \\
\hline \multicolumn{6}{|l|}{ Professional profile } \\
\hline Student & 13.2 & 52.1 & 9.9 & 24.8 & \multirow[t]{3}{*}{$<0.001$} \\
\hline Unemployed & 26.9 & 57.7 & 3.8 & 11.5 & \\
\hline Employed & 23.3 & 64.5 & 4.4 & 7.8 & \\
\hline \multicolumn{6}{|l|}{ BMI $\left(\mathrm{kg} / \mathrm{m}^{2}\right)$} \\
\hline Normal-weight & 9.9 & 69.8 & 7.3 & 12.9 & \multirow[t]{3}{*}{$<0.001$} \\
\hline Overweight & 28.4 & 53.1 & 4.9 & 13.6 & \\
\hline Obesity & 45.3 & 41.5 & 1.9 & 11.3 & \\
\hline \multicolumn{6}{|l|}{ LTPA } \\
\hline Yes & 18.8 & 63.6 & 6.7 & 10.9 & \multirow[t]{3}{*}{0.073} \\
\hline No & 23.8 & 54.6 & 3.8 & 17.7 & \\
\hline Women $(n=630)$ & 17.5 & 63.0 & 4.1 & 15.4 & \\
\hline \multicolumn{6}{|l|}{ Age (years) } \\
\hline $18-35$ & 14.0 & 64.6 & 5.6 & 15.9 & \multirow[t]{2}{*}{0.009} \\
\hline $36-55$ & 22.6 & 60.7 & 2.0 & 14.7 & \\
\hline \multicolumn{6}{|l|}{ Origin } \\
\hline Balearic Islands & 16.4 & 64.2 & 3.9 & 15.6 & \multirow[t]{4}{*}{0.186} \\
\hline Regions of Spain & 19.8 & 64.9 & 2.3 & 13.0 & \\
\hline South America & 14.9 & 59.7 & 4.5 & 20.9 & \\
\hline Other countries & 30.4 & 47.8 & 13.0 & 8.7 & \\
\hline \multicolumn{6}{|l|}{ Educational level } \\
\hline Low & 14.6 & 58.3 & 6.3 & 20.8 & \multirow[t]{3}{*}{0.373} \\
\hline Medium & 18.3 & 60.5 & 4.2 & 17.0 & \\
\hline High & 17.3 & 67.7 & 3.1 & 11.9 & \\
\hline \multicolumn{6}{|l|}{ Professional profile } \\
\hline Student & 12.3 & 59.0 & 4.9 & 23.8 & \multirow[t]{3}{*}{0.010} \\
\hline Unemployed & 25.0 & 51.8 & 1.8 & 21.4 & \\
\hline Employed & 18.4 & 65.3 & 4.3 & 12.0 & \\
\hline \multicolumn{6}{|l|}{ BMI $\left(\mathrm{kg} / \mathrm{m}^{2}\right)$} \\
\hline Normal-weight & 11.3 & 70.7 & 4.4 & 13.6 & $<0.001$ \\
\hline
\end{tabular}


Table 2 Weight Estimation according to socio-demographic variables, BMI distribution and LTPA, a,c (Continued)

\begin{tabular}{lllll}
\hline Overweight & 25.6 & 53.2 & 2.6 & 18.6 \\
Obesity & 36.8 & 38.2 & 2.9 & 22.1 \\
LTPA & & & & \\
Yes & 18.9 & 66.4 & 2.5 & 12.3 \\
No & 16.3 & 59.0 & 5.9 & 18.9
\end{tabular}

Abbreviations: BMI body mass index, LTPA leisure-time physical activity

${ }^{a}$ Values are expressed as percentages

${ }^{b}$ Significant trends between Weight Estimation groups have been evaluated by $x^{2}$

'Significant trends between males and females have been evaluated by $X^{2}:+p<0.05 ; \neq p<0.01 ; \S p<0.001$

\section{Current dieting}

Current dieting was evaluated using the following question: "Are you currently dieting?". The answers were limited to: 'Yes' or 'No'.

\section{Socio-economic and lifestyle factors}

A questionnaire including the following questions was used: age group (young adults, aged 18-35; middle-aged adults, aged 36-55); place of birth (Balearic Islands; other regions in Spain; South America; other countries); educational level (grouped according to years and type of education: low, $<6$ years at school; medium, 6-12 years of education; high, $>12$ years of education); professional profile (student; unemployed -including homemaker, incapacity, retired-; employed); and leisure-time physical activity (LTPA) was evaluated according to guidelines for data processing and analysis of the International Physical Activity Questionnaire 2.0 [27] in the short form. On the basis of their total weekly (wk) time of moderate or vigorous physical activity, the subjects were divided into 2 groups: no, <150 $\mathrm{min} / \mathrm{week}$, and yes, $\geq 150 \mathrm{~min} /$ week.

\section{Statistics}

Analyses were performed with the SPSS statistical software package version 21.0 (SPSS Inc., Chicago, IL, USA). Significant differences were estimated between categories of each of variables listed: Weight Estimation, Weight Concern, Body Image Satisfaction and Current Dieting groups were calculated by chi-square $\left(\chi^{2}\right)$. Significant differences between males and females were also tested by $\chi^{2}$. Logistic regression models were used to estimate the odds ratios (OR) and 95\% confidence intervals (CIs) to examine the possible associations between body image satisfaction, weight concern and current dieting (dependent variables) and sex, professional profile, BMI distribution and LTPA (independent variables). Statistical significance was considered at an alpha of 0.05 .

\section{Results}

\section{Weight estimation}

Around 14\% of the study population did not report their current weight (12.9\% males; $15.4 \%$ females) (Table 2$)$.
For both male and female participants, the prevalence of middle-aged adults who underestimated their current weight was higher than youngers, and the prevalence of middle-aged participants who overestimated current weight was lower. Differences in weight estimation by professional profile were also observed in both sexes. Females who were employed were also more likely to report their current weight correctly compared to their unemployed counterparts. For BMI status: $24.9 \%$ of overweight/obese males and $40.7 \%$ of females did not report their current weight. Underestimation of body weight was observed in $30.8 \%$ of excessive weight sample. Underestimation was also shown by around a quarter of overweight males and females, and $45.3 \%$ of obese males and $36.8 \%$ females. More active males and females reported their current weight correctly.

\section{Body image satisfaction}

Three quarters of the population reported body image dissatisfaction (Table 3) with significant differences between males and females (67.1\% males; $81.0 \%$ females). Females were 2.84 times more likely (95\%CI: $2.17-3.72$ ) to be dissatisfied with being overweight and 0.27 times less (95\%CI: 0.16-0.44) dissatisfied with being underweight than males (data not shown). The prevalence of middle-aged adults dissatisfied with their body image was higher than in the youngers; dissatisfaction with being overweight was higher in middle-aged adults, and with being underweight in young adults. Place of birth, professional profile, and employment status influenced body satisfaction. More overweight males were satisfied with their body image than females, but more overweight males were satisfied with their weight than obese males. Active participants were more satisfied with body image than no actives.

\section{Weight concern}

Around $50 \%$ of the study population reported that they were not worried about their weight (Table 4). More females than males reported to be worried about their weight. In both sexes, more middle-aged adults were worried about weight gain than young adults. Latin American (the largest foreign colony) and unemployed 
Table 3 Body Image Satisfaction according to socio-demographic variables, BMI distribution and LTPA,b,c

\begin{tabular}{|c|c|c|c|c|}
\hline & Dissatisfied being underweight & Satisfied & Dissatisfied being overweight & $P$ \\
\hline Men $(n=451)$ & $15.3 \S$ & $32.9 \S$ & $51.8 \S$ & \\
\hline \multicolumn{5}{|l|}{ Age (years) } \\
\hline $18-35$ & $19.6 \S$ & $35.8 \S$ & $44.5 \S$ & \multirow[t]{2}{*}{$<0.001$} \\
\hline $36-55$ & 4.1 & $25.2+$ & $70.7 \neq$ & \\
\hline \multicolumn{5}{|l|}{ Origin } \\
\hline Balearic Islands & $15.8 \S$ & $27.9+$ & $56.4 \S$ & \multirow[t]{4}{*}{0.132} \\
\hline Regions of Spain & $11.4 \dagger$ & $42.0 \neq$ & $46.6 \S$ & \\
\hline South America & 14.8 & $40.7 \neq$ & $44.4 \ddagger$ & \\
\hline Other countries & 17.6 & $47.1 \neq$ & $35.3 \neq$ & \\
\hline \multicolumn{5}{|l|}{ Educational level } \\
\hline Low & 10.3 & $37.9+$ & $51.7 \neq$ & \multirow[t]{3}{*}{0.255} \\
\hline Medium & $18.1 \S$ & $33.5 \S$ & $48.4 \S$ & \\
\hline High & $11.7 \neq$ & $30.7+$ & $57.7 \S$ & \\
\hline \multicolumn{5}{|l|}{ Professional profile } \\
\hline Student & $25.4 \ddagger$ & $28.8+$ & $45.8 \S$ & \multirow[t]{3}{*}{0.008} \\
\hline Unemployed & 4.0 & $40.0 \neq$ & $56.0 \neq$ & \\
\hline Employed & $12.3 \S$ & $33.8 \S$ & $53.9 \S$ & \\
\hline \multicolumn{5}{|l|}{ BMI $\left(\mathrm{kg} / \mathrm{m}^{2}\right)$} \\
\hline Normal-weight & $27.2 \S$ & $46.5 \S$ & $26.3 \S$ & \multirow[t]{3}{*}{$<0.001$} \\
\hline Overweight & 1.9 & $21.1 \S$ & $77.0 \S$ & \\
\hline Obesity & 2.0 & 7.8 & $90.2 \dagger$ & \\
\hline \multicolumn{5}{|l|}{ LTPA } \\
\hline Yes & $15.3 \S$ & $36.0 \S$ & $48.7 \S$ & \multirow[t]{3}{*}{0.032} \\
\hline No & $14.1 \neq$ & $24.2+$ & $61.7 \S$ & \\
\hline Women $(n=630)$ & $3.9 \S$ & $19.0 \S$ & $77.1 \S$ & \\
\hline \multicolumn{5}{|l|}{ Age (years) } \\
\hline $18-35$ & $5.6 \S$ & $21.4 \S$ & $73.0 \S$ & \multirow[t]{2}{*}{0.002} \\
\hline $36-55$ & 1.2 & $15.4 \dagger$ & $83.3 \ddagger$ & \\
\hline \multicolumn{5}{|l|}{ Origin } \\
\hline Balearic Islands & $2.9 \S$ & $19.5+$ & $77.6 \S$ & \multirow[t]{4}{*}{0.034} \\
\hline Regions of Spain & $3.1+$ & $23.3 \ddagger$ & $73.6 \S$ & \\
\hline South America & 10.6 & $12.1 \neq$ & $77.3 \ddagger$ & \\
\hline Other countries & 4.3 & $8.7 \neq$ & $87.0 \neq$ & \\
\hline \multicolumn{5}{|l|}{ Educational level } \\
\hline Low & 4.3 & $14.9+$ & $80.9 \neq$ & \multirow[t]{3}{*}{0.849} \\
\hline Medium & $4.2 \S$ & $18.3 \S$ & $77.5 \S$ & \\
\hline High & $3.5 \neq$ & $20.9+$ & $75.6 \S$ & \\
\hline \multicolumn{5}{|l|}{ Professional profile } \\
\hline Student & $9.1 \neq$ & $17.4 \dagger$ & $73.6 \S$ & \multirow[t]{3}{*}{0.007} \\
\hline Unemployed & 1.8 & $10.9 \neq$ & $87.3 \ddagger$ & \\
\hline Employed & $2.8 \S$ & $20.7 \S$ & $76.6 \S$ & \\
\hline \multicolumn{5}{|l|}{ BMI $\left(\mathrm{kg} / \mathrm{m}^{2}\right)$} \\
\hline Normal-weight & $4.5 \S$ & $27.5 \S$ & $68.1 \S$ & $<0.001$ \\
\hline
\end{tabular}


Table 3 Body Image Satisfaction according to socio-demographic variables, BMI distribution and LTPA,b,c (Continued)

\begin{tabular}{llll}
\hline Overweight & 0.6 & $1.9 \S$ & $97.4 \S$ \\
Obesity & 0.0 & 1.5 & $98.5 \dagger$ \\
LTPA & & & \\
Yes & $1.9 \S$ & $22.6 \S$ & $75.5 \S$ \\
No & $6.0 \neq$ & $15.3 \dagger$ & $78.7 \S$
\end{tabular}

Abbreviations: $B M I$ body mass index, LTPA, leisure-time physical activity

${ }^{a}$ Values are expressed as percentages

${ }^{b}$ Significant trends between Weight Estimation groups have been evaluated by $X^{2}$

'Significant trends between males and females have been evaluated by $x^{2}:+p<0.05 ; \neq p<0.01 ; \S p<0.001$

females were the most worried about weight gain. Around $45 \%$ of males and $20.7 \%$ of overweight females reported to be not worried about weight gain, and 59.2\% of obese males and $24.2 \%$ of obese females also reported it. Only one in ten obese males and one in three obese females reported to be very worried about gain weight.

\section{Current dieting}

Fourteen per cent of the study population (18.2\% of overweight and $30.0 \%$ of obese) reported current dieting (Table 5). More active males reported current dieting (14.5\%) than inactive males (7.3\%).

\section{Discussion}

Self-perception of body shape is an important factor in weight control practices [28-34]. This study has assessed body weight satisfaction, acceptance of body image, weight concerns and dieting habits among a Mediterranean adult population. Main findings of the study were that three quarters of the studied Mediterranean adult population reported body image dissatisfaction, males with underweight and females with overweight; middleaged adults perceived their body shape to be larger and were more likely to underestimate their body weight; half of the population were not worried about their body weight, but females were more worried than males; employment status, origin of people, BMI status, and to be active or not are factors that influence body satisfaction.

Self-perceived body image is an important factor for eating habits and life-style behaviors. While some researchers proposed body weight dissatisfaction as an important factor in preventing weight gain and promoting weight loss [28, 29], other researchers proposed body weight dissatisfaction as a driver of unhealthy dieting behaviors [30, 31]. Despite males showing higher excessive weight prevalence, females were more likely to be dissatisfied with their body image than males, reflecting that body and physical appearance seem to be more important in females than males, which are in align with previous studies [32, 33]. As it has been above mentioned, the 'ideal body' usually managed by popular culture and mass media is a tall and thin frame which typically does not reflect average women developing severe opinion of their self-image and hence unnecessarily worried about their weight [32-34]. Of importance, our results support notion that females are more likely to be concerned with their body weight compared to males [34].

Our results also support the results of previous studies that showed that older participants were more likely to underestimate their current weight [10], and to be dissatisfied with their body image. Young people tend to perceive themselves as having higher body weight than older people do [21, 35-37], and in accordance with previous studies, the desire to lose weight increases with the age in males [38].

Some studies showed that the unemployed population perceived themselves as having bad health $[39,40]$. Unemployment is also linked to increased health factor risks such as obesity [41], amongst other habits such as smoking and alcohol and drug consumption. Our results are in accordance with a previous work [42], which showed that unemployed women were more concerned with their appearance.

Reported body image differences among females from different countries and ethnicities have also been reported previously [20], suggesting the need to include nationality and place of birth in the evaluation of body image [43]. Our results showed that Latin American females were more likely to be dissatisfied with being underweight and were more worried about this than their counterparts. Controversial results were obtained in previous studies of body image perception among Latin American females [28, 44]. Despite the fact that Latin American females showed a higher preference for a voluminous body shape than women born in the USA [28], other study [44] reported that Latin America females showed the same body image dissatisfaction as females born in USA. In fact, in some cultures larger body size was traditionally linked to prosperity [10]. Previously, it has been also reported similar body image dissatisfaction among Latin American, Asian or Caucasian females [45]. On the other hand, in 2002, a Spanish study revealed that Mexican females were more likely to be dissatisfied with their bodies than Spanish females, showing a higher preference for slimmer bodies [46]. 
Table 4 Weight Concern according to socio-demographic variables, BMI distribution and LTPA ${ }^{a, b, c}$

\begin{tabular}{|c|c|c|c|c|}
\hline & Not at all & A little & A lot & $P$ \\
\hline Men $(n=451)$ & $60.6 \S$ & $35.8 \S$ & $3.6 \S$ & \\
\hline \multicolumn{5}{|l|}{ Age (years) } \\
\hline $18-35$ & $65.1 \S$ & $32.9+$ & $2.0 \S$ & \multirow[t]{2}{*}{0.001} \\
\hline $36-55$ & $48.7 \S$ & $43.4 \dagger$ & $8.0+$ & \\
\hline \multicolumn{5}{|l|}{ Origin } \\
\hline Balearic Islands & $59.8 \S$ & $37.0 \neq$ & $3.3 \S$ & \multirow[t]{4}{*}{0.181} \\
\hline Regions of Spain & $57.3 \neq$ & 39.0 & $3.7+$ & \\
\hline South America & $58.3 \neq$ & 29.2 & $12.5+$ & \\
\hline Other countries & $81.3 \neq$ & 18.8 & 0.0 & \\
\hline \multicolumn{5}{|l|}{ Educational level } \\
\hline Low & $57.1+$ & 32.1 & 10.7 & \multirow[t]{3}{*}{0.165} \\
\hline Medium & $63.8 \S$ & $33.2 \neq$ & $3.0 \S$ & \\
\hline High & $56.1 \S$ & $40.5+$ & $3.4 \S$ & \\
\hline \multicolumn{5}{|l|}{ Professional profile } \\
\hline Student & $62.3 \S$ & 34.2 & $3.5 \S$ & \multirow[t]{3}{*}{0.935} \\
\hline Unemployed & $52.2+$ & 43.5 & $4.3+$ & \\
\hline Employed & $60.1 \S$ & $36.2 \S$ & $3.7 \S$ & \\
\hline \multicolumn{5}{|l|}{ BMI $\left(\mathrm{kg} / \mathrm{m}^{2}\right)$} \\
\hline Normal-weight & $71.5 \S$ & $27.1 \S$ & $1.4 \S$ & \multirow[t]{3}{*}{$<0.001$} \\
\hline Overweight & $45.1 \S$ & 50.7 & $4.2 \S$ & \\
\hline Obesity & $59.2 \S$ & 28.6 & $12.2+$ & \\
\hline \multicolumn{5}{|l|}{ LTPA } \\
\hline Yes & $59.2 \S$ & $37.0 \neq$ & $3.8 \S$ & \multirow[t]{3}{*}{0.864} \\
\hline No & $62.1 \S$ & $34.5+$ & $3.4 \S$ & \\
\hline Women $(n=630)$ & $34.1 \S$ & $47.8 \S$ & $18.1 \S$ & \\
\hline \multicolumn{5}{|l|}{ Age (years) } \\
\hline $18-35$ & $38.5 \S$ & $42.2+$ & $19.4 \S$ & \multirow[t]{2}{*}{0.003} \\
\hline $36-55$ & $27.4 \S$ & $56.5+$ & $16.1+$ & \\
\hline \multicolumn{5}{|l|}{ Origin } \\
\hline Balearic Islands & $34.2 \S$ & $49.9 \neq$ & $16.0 \S$ & \multirow[t]{4}{*}{0.019} \\
\hline Regions of Spain & $37.2 \neq$ & 47.9 & $14.9+$ & \\
\hline South America & $27.4 \neq$ & 37.1 & $35.5+$ & \\
\hline Other countries & $38.1 \neq$ & 42.9 & 19.0 & \\
\hline \multicolumn{5}{|l|}{ Educational level } \\
\hline Low & $28.3+$ & 54.3 & 17.4 & \multirow[t]{3}{*}{0.512} \\
\hline Medium & $36.1 \S$ & $44.4 \neq$ & $19.4 \S$ & \\
\hline High & $32.6 \S$ & $51.0+$ & $16.3 \S$ & \\
\hline \multicolumn{5}{|l|}{ Professional profile } \\
\hline Student & $37.4 \S$ & 40.9 & $21.7 \S$ & \multirow[t]{3}{*}{0.052} \\
\hline Unemployed & $26.5+$ & 42.9 & $30.6+$ & \\
\hline Employed & $33.8 \S$ & $50.4 \S$ & $15.8 \S$ & \\
\hline
\end{tabular}

Table 4 Weight Concern according to socio-demographic variables, BMI distribution and LTPA ${ }^{\mathrm{a}, \mathrm{b}, \mathrm{c}}$ (Continued)

\begin{tabular}{lllll}
\hline BMI $\left(\mathrm{kg} / \mathrm{m}^{2}\right)$ & & & & \\
Normal-weight & $39.3 \S$ & $48.5 \S$ & $12.3 \S$ & $<0.001$ \\
Overweight & $20.7 \S$ & 51.0 & $28.3 \S$ & \\
Obesity & $24.2 \S$ & 46.8 & $29.0 \dagger$ & \\
LTPA & & & & \\
Yes & $35.6 \S$ & $49.1 \neq$ & $15.2 \S$ & 0.169 \\
No & $32.4 \S$ & $46.3 \dagger$ & $21.3 \S$ & \\
\hline
\end{tabular}

Abbreviations: $B M I$ body mass index, LTPA leisure-time physical activity

${ }^{a}$ Values are expressed as percentages

${ }^{\mathrm{b}}$ Significant trends between Weight Estimation groups have been evaluated by $X^{2}$

'Significant trends between males and females have been evaluated by $X^{2}$ : $\dagger p<0.05 ; \neq p<0.01 ; \S p<0.001$

Despite media mass and health policies being focused on raising awareness about healthy weights, an increasing number of participants with excessive weight failed to recognize that their weight is a cause of concern [47]. While the general image that the media mass uses is based on slimmer bodies, the severe images that are used to define obesity should be linked to the impression that extremely high weight images are required to define excessive weight $[47,48]$. Fortunately along these lines, our results reported that our overweight participants were more concerned about their weight than normalweight participants were.

Some studies investigated the relationship between LTPA and body image satisfaction with a generally repeated conclusion: LTPA is related to body image satisfaction [48]. Participants doing LTPA are more likely to be satisfied with their body image than participants not doing LTPA with the same BMI [49].

Despite the results showing that only approximately $25 \%$ of the population reported body image satisfaction, just $14.0 \%$ of the population was dieting. Our results, in concordance with earlier studies [50,51], showed that heavier participants were more likely to be on a diet. Moreover, our results highlight that males doing LTPA were more likely to be on diet, which is in agreement with a previous study that reported that masculine gender role endorsement appears to be associated with the development of muscularity-related eating and body image concerns [52].

Finally, the relationship between ideal body image and weight self-regulation process may be found in Higgins' $[53,54]$ regulatory focus theory (RFT). According to RFT, the personal motivation to lose or to maintain weight may be triggered to show an attractive body or to avoid social refection of fatness, being last case more specifically influential on individual who perceives himself/herself more deviant from socially body acceptable. Moreover, for the individual, losing weight is faced by 
Table 5 Current Dieting according to socio-demographic variables, BMI distribution and LTPA ${ }^{a, b, c}$

\begin{tabular}{|c|c|c|c|}
\hline & Yes & No & $P$ \\
\hline Men $(n=451)$ & 14.0 & 86.0 & \\
\hline \multicolumn{4}{|l|}{ Age (years) } \\
\hline $18-35$ & 10.7 & 89.3 & 0.107 \\
\hline $36-55$ & 16.3 & 83.7 & \\
\hline \multicolumn{4}{|l|}{ Origin } \\
\hline Balearic Islands & 13.0 & 87.0 & 0.460 \\
\hline
\end{tabular}

Regions of Spain $\quad 13.6 \quad 86.4$

$\begin{array}{lll}\text { South America } & 12.5 & 87.5\end{array}$

$\begin{array}{lll}\text { Other countries } & 0.0 & 100.0\end{array}$

Educational level

Low

Medium

High

Professional profile

Student

Unemployed

Employed

BMI $\left(\mathrm{kg} / \mathrm{m}^{2}\right)$

Normal-weight

\section{Overweight}

LTPA

Yes

No

Women $(n=630)$

Age (years)

$$
\text { 18-35 }
$$

36-55

Origin

Balearic Islands

Regions of Spain

South America

Other countries

Educational level

Low
Medium
High
Professional profile
Student
Unemployed
Employed

0.964

Table 5 Current Dieting according to socio-demographic variables, BMI distribution and LTPA $A^{\mathrm{a}, \mathrm{b}, \mathrm{c}}$ (Continued)

\begin{tabular}{llll} 
BMI $\left(\mathrm{kg} / \mathrm{m}^{2}\right)$ & & & \\
Normal-weight & 10.5 & 89.5 & $<0.001$ \\
Overweight & 20.9 & 79.1 & \\
Obesity & 34.3 & 65.7 & \\
LTPA & & & 0.227 \\
Yes & 17.2 & 82.8 & \\
No & 13.7 & 86.3 & \\
\hline
\end{tabular}

Abbreviations: BMI body mass index, LTPA leisure-time physical activity

${ }^{a}$ Values are expressed as percentages

${ }^{\mathrm{b}}$ Significant trends between Weight Estimation groups have been evaluated by $x^{2}$

'Significant trends between males and females have been evaluated by $\chi^{2}$ : $\dagger p<0.05 ; \neq p<0.01 ; \S p<0.001$

obstacles on psychological, cognitive and emotional levels due to sacrifices demanded by weight selfregulatory behaviors that may dissuade many males and females. Moreover, an "ideal state" of prescription and enforcement of body shape looks like is a very sensitive, political and controversial topic that should be arranged someday. Nevertheless, new education and/or awareness strategies for promoting positive body image attitudes are needed, as well as it is compulsory to define the role that different healthcare providers, or community members, or other professions can play in promotion positive self-esteem and body image.

\section{Conclusions}

Three quarters of the studied Mediterranean adult population reported body image dissatisfaction, but almost half of the population reported that they were not worried about their body weight. In particular, females were more likely to be concerned about their body weight status compared with males, and practice of physical activity is a positive factor in self-perception. Holistic strategies are needed to avoid promoting unreal bodies. New strategies that include education, awareness, health, social education, etc., should be developed. In the next future, a new social environment which fosters the perception and acceptance of the real body image, avoiding distortions, and therefore future pathologies, should be developed.

\section{Abbreviations}

BMI: Body mass index; Cl: Confidence interval; LTPA: Leisure-time physical activity; OR: Odds ratio; SPSS: Statistical Package for the Social Sciences; WHO: World Health Organization

\section{Acknowledgments}

Not applicable.

\section{Funding}

This study was supported by the Instituto de Salud Carlos III, (Projects 11/ 01791, 14/00636, Red Predimed-RETIC RD06/0045/1004, and CIBEROBN CB12/ 03/30038), Grant of support to research groups no. 35/2011 (Balearic Islands 
Gov.) and EU FEDER funds. The funders had no role in the design or conduct of the study; collection, management, analysis and interpretation of the data; or preparation, review and approval of the manuscript.

\section{Availability of data and materials}

The data analysed in this paper can be made available to researchers. Requests for access to the dataset used in this paper should be directed to the corresponding author.

\section{Authors' contribution}

$M M B, J P, A P$ and JAT designed the study and wrote the protocol. JLC and MMB collected data and conducted literature searches and provided summaries of previous research studies. JLC and MMB conducted the statistical analysis. JLC, MMB, and JAT wrote the first draft of the manuscript. All read and approved the final manuscript.

\section{Competing interests}

The authors declare that they have no competing interests.

\section{Consent for publication}

Not applicable.

\section{Ethics approval and consent to participate}

The study was conducted according to the guidelines laid down in the Declaration of Helsinki, and all procedures were approved by the Balearic Islands Ethics Committee (ref. IB/1128/09 PI). Written informed consent was obtained from all participants.

Received: 2 July 2016 Accepted: 8 December 2016

Published online: 06 January 2017

\section{References}

1. Centers for Disease Control and Prevention. Adult Obesity Causes \& Consequences. 2016. Available at: https://www.cdc.gov/obesity/adult/ causes.html. Accessed 23 Oct 2016.

2. Harvard TH Chan School of Public Health. 2016. Obesity Prevention Source: Health risks. Available at: https://www.hsph.harvard.edu/obesity-preventionsource/obesity-consequences/health-effects/ Accessed 23 Oct 2016.

3. Harvard TH Chan School of Public Health. 2016. Obesity Prevention Source: Economic costs. Available at: https://www.hsph.harvard.edu/obesityprevention-source/obesity-consequences/economic/ Accessed 23 Oct 2016.

4. World Health Organization. 2016. Obesity and overweight. Avalaible at: http://www.who.int/mediacentre/factsheets/fs311/en/index.html. Accessed 7 July 2015.

5. Rodríguez-Rodríguez E, López-Plaza B, López-Sobaler AM, Ortega RM. Prevalencia de sobrepeso y obesidad en adultos españoles. Nutr Hospitalaria. 2011:26:355-63.

6. Mokdad AH, Bowman BA, Ford ES, Vinicor F, Marks JS, Koplan JP. The continuing epidemics of obesity and diabetes in the United States. J Am Med Ass. 2001;286:1195-200

7. Zaninotto P, Head J, Stamatakis E, Wardle H, Mindell J. Trends in obesity among adults in England from 1993 to 2004 by age and social class and projections of prevalence to 2012. J Epidemiol Comm Health. 2009;63:140-6.

8. Mokdad AH, Ford ES, Bowman BA, Dietz WH, Vinicor F, Bales VS, et al. Prevalence of obesity, diabetes, and obesity-related health risk factors. J Am Med Ass. 2003;283:76-9.

9. Dastgiri S, Mahdavi R, TuTunchi H, Faramarzi E. Prevalence of obesity, food choices and socioeconomic status: a cross-sectional study in the north-west of Iran. Public Health Nutr. 2006;9:996-1000.

10. Leung J, Burke B, Ford D, Garvin G, Korn C, Sulis C, et al. Possible association between obesity and Clostridium difficile infection. Emerg Infect Dis. 2013;19: 1791-8.

11. Wing RR. Long-term effects of a lifestyle intervention on weight and cardiovascular risk factors in individuals with type 2 diabetes mellitus: four-year results of the Look AHEAD trial. Arch Intern Med. 2010;170:1566-75.

12. Dengo AL, Dennis EA, Orr JS, Marinik EL, Ehrlich E, Davy BM, et al. Arterial destiffening with weight loss in overweight and obese middle-aged and older adults. Hypertension. 2010;55:855-61.

13. de Las Fuentes L, Waggoner AD, Mohammed BS, Stein RI, Miller 3rd BV, Foster GD, et al. Effect of moderate diet-induced weight loss and weight regain on cardiovascular structure and function. J Am Coll Cardiol. 2009;54: 2376-81.

14. Bhanji S, Khuwaja AK, Siddiqui F, Azam I, Kazmi K. Underestimation of weight and its associated factors among overweight and obese adults in Pakistan: a cross sectional study. BMC Public Health. 2011;11:363.

15. Connor-Gorber S, Tremblay M, Moher D, Gorber B. A comparison of direct vs. self-report measures for assessing height, weight and body mass index: a systematic review. Obes Rev. 2007;8:307-26.

16. Makara-Studzińska M, Podstawka D, Goclon K. Factors influencing selfperception of overweight people. Pol Merk Lek. 2013;35:313-5.

17. Groesz LM, Levine MP, Murnen SK. The effect of experimental presentation of thin media images on body dissatisfaction: A Meta-Analytics review. Int J Eating Dis. 2002;31:1-16.

18. Becker AE. Television, disordered eating, and young women in Fiji: negotiating body image and identity during rapid social change. Cult Med Psyc. 2004;28:533-59.

19. Calado M, Lameiras M, Sepulveda AR, Rodriguez Y, Carrera MV. The association between exposure to mass media and body dissatisfaction among Spanish adolescent. Womens Health Issues. 2011;21:390-9.

20. Sciacca JP, Melby CL, Hyner GC, Brown AC, Femea PL. Body Mass Index and perceived weight status in young adults. J Comm Health. 1991;16:159-68.

21. Rodin J. Cultural and psychosocial determinants of weight concerns. Ann Int Med. 1993;119:643-5.

22. Wronka I, Suliga E, Pawlińska-Chmara R. Perceived and desired body weight among female university students in relation to BMI-based weight status and socio-economic factors. Ann Agric Environ Med. 2013;20:533-8.

23. Johnson F, Cooke L, Croker H, Wardle J. Changing perceptions of weight in Great Britain: comparison of two population surveys. Brit Med J. 2008:337:a494.

24. Coll JL, Bibiloni MM, Salas R, Pons A, Tur JA. Prevalence and related risk factors of overweight and obesity among the adult population in the Balearic islands, a Mediterranean region. Obes Facts. 2015:8:220-33.

25. Brestoff JR, Perry IJ, Van den Broeck J. Challenging the role of social norms regarding body weight as an explanation for weight, height, and BMl misreporting biases: development and application of a new approach to examining misreporting and misclassification bias in surveys. BMC Public Health. 2011;11:331.

26. Stunkard AJ, Sorenson T, Schulsinger F. Use of the Danish adoption register for the study of obesity and thinness. Res Publ Assoc Res Nerv Ment Dis. 1983;60:115-20.

27. IPAQ - International Physical Activity Questionnaire. Guide-lines for data processing and analysis of the International Physical Activity Questionnaire (IPAQ). Available at: https://sites.google.com/site/theipaq/ Accessed 25 Oct 2016.

28. Anderson LA, Eyler AA, Galuska DA, Brown DR, Brownson RC. Relationship of satisfaction with body size and trying to lose weight in a national survey of overweight and obese women aged 40 and older, United States. Prev Med. 2002;35:390-6.

29. Cash TF, Melnyk SE, Hrabosky Jl. The assessment of body image investment: an extensive revision of the appearance schemas inventory. Int J Eating Dis. 2004:35:305-16.

30. Millstein RA, Carlson SA, Fulton JE, Galuska DA, Zhang J, Blanck HM, et al. Relationships between body size satisfaction and weight control practices among US adults. Medscape J Med. 2008;19:119.

31. Duncan DT, Wolin KY, Scharoun-Lee M, Ding EL, Warner ET, Bennett GG. Does perception equal reality? Weight misperception in relation to weight-related attitudes and behaviors among overweight and obese US adults. Int J Behav Nutr Phys Act. 2011;8:20.

32. Yaemsiri S, Slining MM, Agarwal SK. Perceived weight status, overweight diagnosis, and weight control among US adults: the NHANES 2003-2008 Study. Int J Obes (Lond). 2011;35:1063-70.

33. Grogan S. Body image and health: contemporary perspectives. J Health Psychol. 2006;11:523-30.

34. Forrester-Knauss C, Zemp-Stutz E. Gender differences in disordered eating and weight dissatisfaction in Swiss adults: which factors matter? BMC Pub Health. 2012;12:809.

35. Goryński P, Krzyzanowski M. A study of the self-perception of being overweight in adult inhabitants of Cracow. J Clin Epidemiol. 1989;42: 1149-54.

36. Blokstra A, Burns CM, Seidell JC. Perception of weight status and dieting behaviour in Dutch men and women. Int J Obes. 1999;23:7-17. 
37. Hossain P, Kawar B, El Nahas M. Obesity and diabetes in the developing world-a growing challenge. New Eng J Med. 2007;18:213-5.

38. McCabe MP, Ricciardelli LA. Body image dissatisfaction among males across the lifespan: a review of past literature. J Psychosom Res. 2004;56:675-85.

39. Amstadter AB, Begle AM, Cisler JM, Hernandez MA, Muzzy W, Acierno R. Prevalence and correlates of poor self-rated health in the United States: the national elder mistreatment study. Am J Geriat Psych. 2010;18:615-23.

40. Franzini L, Giannoni M. Determinants of health disparities between Italian regions. BMC Pub Health. 2010;10:296.

41. Hollederer A. Unemployment and health in the German population: results from 2005 microcensus. J Pub Health. 2011;19:257-68.

42. Hayes D, Ross CE. Concern with appearance. Health beliefs and eating habits. J Health Soc Behav. 1987;28:120-30.

43. Kronenfeld LW, Reba-Harrelson L, Von Holle A, Reyes ML, Bulik CM. Ethnic and racial differences in body size perception and satisfaction. Body Image. 2010;7:131-6.

44. Lopez E, Blix GG, Blix AG. Body image of Latinas compared to body image of non-Latina White women. Health Val. 1995;19:3-10.

45. Robinson TN, Killen JD, Litt IF, Hammer LD, Wilson DM, Haydel KF, et al. Ethnicity and body dissatisfaction: are Hispanic and Asian girls at increased risk for eating disorders? J Adol Health. 1996;19:384-93.

46. Rodríguez S, Cruz S. Evaluación de la imagen corporal en mujeres latinoamericanas residentes en Guipúzcoa. Un estudio exploratorio. Anal Psicol. 2006;22:186-9.

47. Crawford D, Campbell K. Lay definitions of ideal weight and overweight. Int J Obes. 1999;23:738-45.

48. Alley TR. Visual detection of body-weight change in young women. Percept Motor Skills. 1991;73:904-6.

49. Blake CE, Hébert JR, Lee DC, Adams SA, Steck SE, Sui X, et al. Adults with greater weight satisfaction report more positive health behaviors and have better health status regardless of BMI. J Obes. 2013;2013:291371.

50. Markey CN, Markey PM. Relations between body image and dieting behaviors: an examination of gender differences. Sex Roles. 2005;53:519-30.

51. Mostafavi-Darani F, Daniali SS, Azadbakht L. Relationship of body satisfaction, with nutrition and weight control behaviors in women. Int Prev Med. 2013;4:467-74.

52. Murray SB, Rieger E, Karlov L, Touyz SW. Masculinity and femininity in the divergence of male body image concerns. J Eat Disord. 2013;1:11.

53. Higgins ET. Beyond pleasure and pain. Am Psychol. 1997;52:1280-300.

54. Higgins ET. Promotion and prevention: regulatory focus as a motivational principle. In: Zanna MP, editor. Advances in experimental social psychology. San Diego: Academic; 1998. p. 1-46.

\section{Submit your next manuscript to BioMed Central and we will help you at every step:}

- We accept pre-submission inquiries

- Our selector tool helps you to find the most relevant journal

- We provide round the clock customer support

- Convenient online submission

- Thorough peer review

- Inclusion in PubMed and all major indexing services

- Maximum visibility for your research

Submit your manuscript at www.biomedcentral.com/submit
Biomed Central 